\title{
EVIDENCE OF OXYGEN SEGREGATION AT Ag/MgO INTERFACES
}

\author{
E. PIPPEL ${ }^{1}$, J. WOLTERSDORF ${ }^{1}$, J. GEGNER ${ }^{2}$ and R. KIRCHHEIM ${ }^{3 \dagger} \uparrow$ \\ ${ }^{1}$ Max-Planck-Institut für Mikrostrukturphysik, Weinberg 2, D-06120 Halle, Germany, ${ }^{2}$ Loctite \\ Research, Gutenbergstraße 3, D-85748 Garching, Germany and ${ }^{3}$ Universität Göttingen, Institut für \\ Materialphysik, Hospitalstr. 3-7, D-37073 Göttingen, Germany
}

(Received 4 November 1999; accepted 14 February 2000)

\begin{abstract}
The distribution and microstructure of $\mathrm{MgO}$ precipitates formed by internal oxidation of $\mathrm{Ag} /$ 3 at. $\% \mathrm{Mg}$ alloys have been investigated by high voltage (HVEM) and high resolution electron microscopy (HREM). The chemical composition of their phase boundaries was studied at an atomic level by electron energy loss (EELS) fine structure analyses especially at the ionization edges (ELNES). In specimens annealed in vacuum $\left(T=1163 \mathrm{~K}\right.$, total pressure about $\left.10^{-3} \mathrm{~Pa}\right)$, oxygen occurs at the interface only, bound as $\mathrm{MgO}$. However, if the samples are annealed in oxygen $\left(T=673 \mathrm{~K}\right.$, partial pressure $\left.10^{5} \mathrm{~Pa}\right)$, the spatially resolved fine structure of the energy loss $\mathrm{O}-\mathrm{K}$ edge reveals an additional interface bonding part, representing an $\operatorname{Ag}_{2} \mathrm{O}$-like bonding state. Thus, with high oxygen activities, the interface layer between magnesia and silver consists of oxygen atoms bound partly as $\mathrm{MgO}$ and as $\mathrm{Ag}_{2} \mathrm{O}$. This segregation of excess oxygen at the $\mathrm{Ag} / \mathrm{MgO}$ interfaces fits into the framework of a general structural model, which should be applicable to many metal/oxide phase boundaries. (C) 2000 Acta Metallurgica Inc. Published by Elsevier Science Ltd. All rights reserved.
\end{abstract}

Keywords: Transmission electron microscopy (TEM); Electron energy loss spectroscopy (EELS); Internal oxidation; Interface; Segregation

\section{INTRODUCTION}

Metal/ceramic phase boundaries are of great importance for many applications in materials science $[1,2]$, for instance, to thin solid films, coatings, electronic packaging, supported catalysts, and fibre-reinforced metal-matrix composites. In many dispersion-hardened materials, metal/oxide interfaces are involved in the strengthening mechanisms [3]. They are also included in microminiature electronic devices (MOS applications as, e.g. MOSFETs). Therefore, investigations into the bonding mechanisms and nanochemistry of metal/ ceramic interfaces have been intensified in recent years (e.g. Refs [4-7]).

For reasons of energy, defects at interphase boundaries promote segregation of impurity atoms, which are dissolved in the bulk. Detailed knowledge of this effect is of great importance, as the solute atoms can influence the characteristics of the material [8] as observed, for instance, in the interfacial accumulation of $\mathrm{Ag}$ at $\mathrm{MgO} / \mathrm{Cu}\{222\}$, and $\mathrm{of} \mathrm{Sb} /$ $\mathrm{Zn}$ at $\mathrm{Ag} / \mathrm{Mn}_{3} \mathrm{O}_{4}[9,10]$. Furthermore, the segre-

$\uparrow$ To whom all correspondence should be addressed. gation of oxygen modifies the chemical composition of metal/oxide interfaces as a function of the activity of oxygen. For some systems it was shown that after internal oxidation at high oxygen partial pressures the terminal layers of the oxide lattice are close-packed oxygen planes [11-16]. On the other hand, at low oxygen activities only partly occupied oxygen layers terminate the ceramic component [13]. The system $\mathrm{Cu} / \mathrm{MgO}$, preferentially used for such investigations [5, 6, 9, 14-23], reveals that the composition of the final polar (111) magnesia plane varies from partial to full oxygen occupancy with increasing oxygen activity. Interfacial copper, however, changes its bonding state from metallic to oxidic $\left(\mathrm{Cu}_{2} \mathrm{O}\right)$ simultaneously [7, 24]. This result is in agreement with investigations of the systems $\mathrm{Cu}$ / $\mathrm{Al}_{2} \mathrm{O}_{3}$ and $\mathrm{Ag} / \mathrm{MgO}$ and of other oxides with palladium as the metallic component [25-29].

To investigate metal/oxide interphase boundaries, spatially resolved EDX [30], surface spectroscopy [31], high resolution electron microscopy (HREM) [5, 11-13, 21, 23, 32-34], and field-ion microscopy with atom-probe (FIP-AP) [9, 14, 15, 35] have so far been applied successfully. Electron energy loss spectroscopy (EELS) is also useful in performing such examinations, since it allows the bonding 
states of chemical elements at interfaces to be determined on a nanometre scale by analysing the near edge fine structure (ELNES) of an EELS spectrum [7, 24, 28, 29, 36, 37]. Moreover, quantitative volumetric measurements (sorption and desorption of oxygen) [25] and a special electrochemical technique applicable to the matrix metal palladium (high hydrogen permeability) have been employed [2527]. The varying oxygen coverage at the metal/ oxide interface gives rise to varying hydrogen segregation, which was studied extensively by Huang et al. for palladium alloys [26, 27]. There, the excess oxygen forming an oxide with the more noble matrix metal leads to irreversible trapping of hydrogen at the interface, which precedes water formation during the reduction of less noble oxides. Thus, hydrogen acts as a probe for excess oxygen. The interpretation of the experimental results finally yields the model of structural vacancies at the interface first proposed in Ref. [27] and supported by additional evidence in Ref. [25].

In the present work, techniques of high voltage transmission electron microscopy (HVEM), high resolution transmission electron microscopy and electron energy loss spectroscopy have been used to investigate the segregation of oxygen at polar (111) interfaces between $\mathrm{Ag}$ and $\mathrm{MgO}$ precipitates produced by internal oxidation of an $\mathrm{Ag} / \mathrm{Mg}$ alloy. This particular preparation method is advantageous in that flat (on an atomic scale) and low-energetic semi-coherent interfaces with a small lattice misfit of $d=3.1 \%$ are forming $[4,5,9,38]$ as the precipitates (here of $\mathrm{MgO}$ ) are growing freely with respect to shape and orientation. Furthermore, an equilibrium between oxygen at the interface and oxygen dissolved in the matrix is easy to attain, due to the high diffusivity of oxygen in silver, even at moderate temperatures of about $700 \mathrm{~K}$ [39]. Therefore, only rather short annealing times in a desired oxygen atmosphere are necessary to saturate the $\mathrm{Ag} /$ $\mathrm{MgO}$ interface with an excess of oxygen [25, 40]. For the $\mathrm{Ag} / \mathrm{MgO}$ system, enthalpy and entropy of the oxygen segregation as well as equations of isotherms have been determined by volumetric measurements [25], which can be used to interpret our results.

\section{EXPERIMENTAL}

\subsection{Internal oxidation}

An $\mathrm{Ag} / \mathrm{Mg}$ alloy (99.9 and $99.7 \%$ purity, respectively) containing 3.0 at. $\% \mathrm{Mg}$ was produced by arc melting. The solidified bead was then annealed in argon for $24 \mathrm{~h}$ at $1173 \mathrm{~K}$ and cold-rolled to a foil of $150 \mu \mathrm{m}$ in thickness.

From previous investigations it is known that during the internal oxidation of this alloy, small intragranular $\mathrm{MgO}$ particles of about $6 \mathrm{~nm}$ in diameter occur, whereas some larger precipitates of 100
$400 \mathrm{~nm}$ are forming along grain boundaries [25, 40]. To attain a high volume fraction of the larger particles, which is more convenient for TEM investigations, internal oxidation has been performed with no previous recrystallization treatment of the alloy. Hence, the foils were annealed in air at $1173 \mathrm{~K}$ for $48 \mathrm{~h}$, which is sufficient to ensure a complete reaction of the magnesium forming $\mathrm{MgO}$ precipitates. A subsequent wet chemical analysis revealed only a small evaporation loss of $\mathrm{Mg}$. The precipitated $\mathrm{MgO}$ crystallites have formed truncated octahedra with polar $\{111\}_{\mathrm{MgO}} \|\{111\}_{\mathrm{Ag}}$ and non-polar $\{001\}_{\mathrm{MgO}} \|\{001\}_{\mathrm{Ag}}$ interfaces according to their cube-on-cube orientation relationship with the matrix.

\subsection{Sorption and desorption of oxygen}

In order to vary the composition of the $\mathrm{Ag} / \mathrm{MgO}$ interfaces after internal oxidation, half of the $\mathrm{Ag}$ / $\mathrm{MgO}$ material was annealed for $2 \mathrm{~h}$ at $673 \mathrm{~K}$ in a pure oxygen atmosphere at a partial pressure of $10^{5} \mathrm{~Pa}$. This relatively low temperature was chosen to provide a high oxygen coverage at the interfaces as the segregation is exothermic there. The diffusivity of oxygen in silver is high enough to maintain the equilibrium. Under these conditions the solubility of oxygen in the matrix is only 0.001 at.\% [39].

The second part of the material was annealed for $2 \mathrm{~h}$ at $1163 \mathrm{~K}$ in high vacuum (total pressure $10^{-3} \mathrm{~Pa}$, which is also the upper limit for the oxygen partial pressure) to remove almost all oxygen atoms dissolved in the silver matrix during internal oxidation and, for equilibrium reasons, also those covering the $\mathrm{Ag} / \mathrm{MgO}$ interfaces. Thus, even at the phase boundaries, oxygen belonging solely to the stoichiometry of $\mathrm{MgO}$ is expected.

\subsection{Preparation of TEM samples}

The preparation of TEM samples of the internally oxidized $\mathrm{Ag} / \mathrm{Mg}$ foils, heat treated as described above, followed a standard route. First, $3 \mathrm{~mm}$ thin discs were cut from the foils by ultrasonic drilling. Being ground to a thickness of about $100 \mu \mathrm{m}$, the specimen was dimpled on either side to a central thickness of $20 \mu \mathrm{m}$ by diamond tools. Final thinning to electron transparency followed via Ar-ion bombardment in a Gatan DuoMill. An ion beam at a glancing angle of $10^{\circ}$ to the specimen is sufficient to provide a suitably extended area of less than $10 \mathrm{~nm}$ in thickness, close to the hole arising.

\subsection{Microstructural and nanochemical analyses}

HVEM investigations were carried out using a JEOL JEM 1000-06/71 high voltage transmission electron microscope operating at $1 \mathrm{MV}$. In this way, a large specimen area has been analysed to yield a 
detailed survey of the distribution of the $\mathrm{MgO}$ precipitates along the grain boundaries of the $\mathrm{Ag}$ matrix. High resolution transmission electron microscopy studies were then performed in a Philips CM 20 FEG operating at $200 \mathrm{kV}$ and equipped with a post-column electron energy filter (Gatan Imaging Filter GIF 200) for EELS analyses. The thermally assisted field emission gun enables an energy resolution of the EEL spectra of $0.8-1 \mathrm{eV}$, which were usually acquired at a dispersion of $0.5 \mathrm{eV}$ per channel. This yields information on the chemical bonding state of the elements of interest by analysing the ELNES of the relevant ionization edges, which can be attributed to transitions of core-shell electrons into unoccupied states above the Fermi level [41]. With respect to the $\mathrm{Ag} / \mathrm{MgO}$ interface to be examined either point analyses were made, or series of EEL spectra along a line across a well developed (111) matrix/particle interface have been recorded in the scanning transmission (STEM) mode, with the electron probe (diameter about $2 \mathrm{~nm}$ ) digitally scanned by the Gatan Digiscan model 688 .

To obtain chemical information from the interface area, i.e. to extract the interface specific part of the ELNES, the spatial difference technique [28] was applied: as the spectrum of the interface also contains information from the adjacent matrix and precipitation areas (the probe diameter is larger than the thickness of the interface layer) this method requires reference spectra of the precipitation areas in addition to the interface spectrum. Subtracting the suitably scaled (to prevent unphysical negative counts) and background-eliminated reference spectra from the interface spectrum provides information as to the interfacial atoms, particularly, their chemical environment or oxidation state, which may differ from that of the bulk material. This spectrum processing was carried out using the Gatan ELP software.

\section{RESULTS}

\subsection{Size and distribution of the $\mathrm{MgO}$ precipitates}

To characterize the $\mathrm{MgO}$ precipitates formed, the internally oxidized $\mathrm{Ag} / \mathrm{MgO}$ foils were first investigated by HVEM. Large $\mathrm{MgO}$ particles preferentially localized at the grain boundaries of the $\mathrm{Ag}$ matrix occurred in addition to much smaller oxide precipitates in the bulk according to Ref. [25]. Figure 1 presents a HVEM bright-field image of the $\mathrm{Ag} / \mathrm{MgO}$ material typical of both sets of specimens, annealed in vacuum and annealed in oxygen. Large $\mathrm{MgO}$ particles of typically $100 \mathrm{~nm}$ in diameter along the grain boundary (middle) are clearly shown by their light contrast. These precipitates grown by ripening processes have a size suitable for EELS analyses of the $\mathrm{Ag} / \mathrm{MgO}$ interface (see below). Although the Ag matrix recrystallized

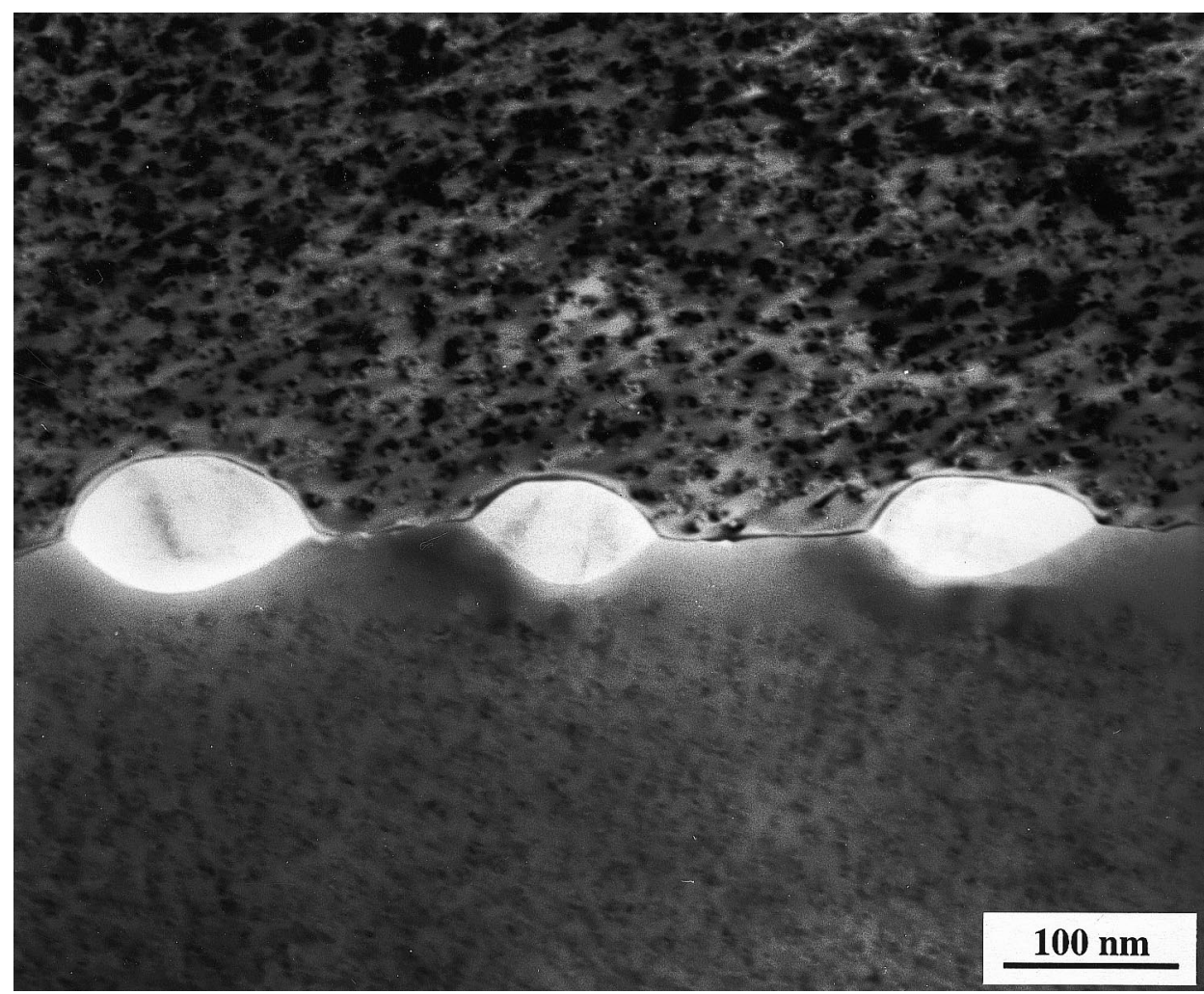

Fig. 1. HVEM image of large $\mathrm{MgO}$ precipitates located at a grain boundary of the Ag matrix. 
during internal oxidation, a small grain size of only a few micrometres was achieved. The foils had been deformed plastically by cold rolling and precipitation. The HREM image of Fig. 2 shows that numerous small $\mathrm{MgO}$ precipitates, typically of about $5 \mathrm{~nm}$ in diameter (occurring already within both grains of Fig. 1) have formed in the silver bulk. They are imaged by their diffraction contrast. Because of the high oxygen affinity of magnesium, even a single molecule of $\mathrm{MgO}$ can build up a stable nucleus. Due to the large interfacial area, these particles provide the large part of the total amount of oxygen atoms segregating at the $\mathrm{Ag} /$ $\mathrm{MgO}$ phase boundaries. However, for an EELS analysis of the interface, these precipitates are less suited as they are smaller than the average foil thickness. Figure 2 also shows that the atomic planes cross the $\mathrm{Ag} / \mathrm{MgO}$ interface continuously with no misfit dislocations forming, i.e. the small magnesia crystals are terminated by a completely coherent interface. There is no reaction zone forming along these boundaries.

\subsection{EELS analyses of the $\mathrm{Ag} / \mathrm{MgO}$ interfaces}

After annealing in oxygen and vacuum, respectively, the chemical composition of the $\mathrm{Ag} / \mathrm{MgO}$ phase boundaries was investigated by interpreting the interface-related features in the spatial resolved
EELS spectra. In particular, the $\mathrm{O}-\mathrm{K}$ ionization edge was analysed in order to determine the bonding state of oxygen across the interface on a nanometre scale to find out whether an oxidized $\mathrm{Ag}$ interlayer has formed, or not. Thus, both kinds of heat treatment (cf. Section 2.2) were compared.

\subsubsection{Specimens annealed in oxygen. A typical} series of EEL spectra along a line across an Ag/ $\mathrm{MgO}$ interface with a large amount of segregated oxygen (annealed in $\mathrm{O}_{2}$ at $673 \mathrm{~K}$ for $2 \mathrm{~h}$ ) is demonstrated in Fig. 3. Crossing the phase boundary from the $\mathrm{MgO}$ crystal to the $\mathrm{Ag}$ matrix at steps of about $2 \mathrm{~nm}$ the K-ionization edge of oxygen disappears, with the $\mathrm{M}_{45}$ edge of silver appearing. These EEL spectra prove that at the interface both shape and onset of the $\mathrm{O}-\mathrm{K}$ edge change significantly with respect to the $\mathrm{MgO}$ side. As these typical fine-structure features of an ionization edge in an EEL spectrum depend on the environment of the target $\mathrm{O}$ atom, the bonding state of oxygen at the interface is different from that in $\mathrm{MgO}$.

The bonding state of oxygen at the $\mathrm{Ag} / \mathrm{MgO}$ phase boundary has been analysed in more detail by separating the EEL spectrum of $\mathrm{MgO}$ from that measured at the interface, as done in Fig. 4. This figure shows the background-subtracted $\mathrm{O}-\mathrm{K}$ edges of $\mathrm{MgO}$ (below) and $\mathrm{Ag}_{2} \mathrm{O}$ (above) from standards together with an interface region, extracted from the middle part of Fig. 3 (curve "interface"). The

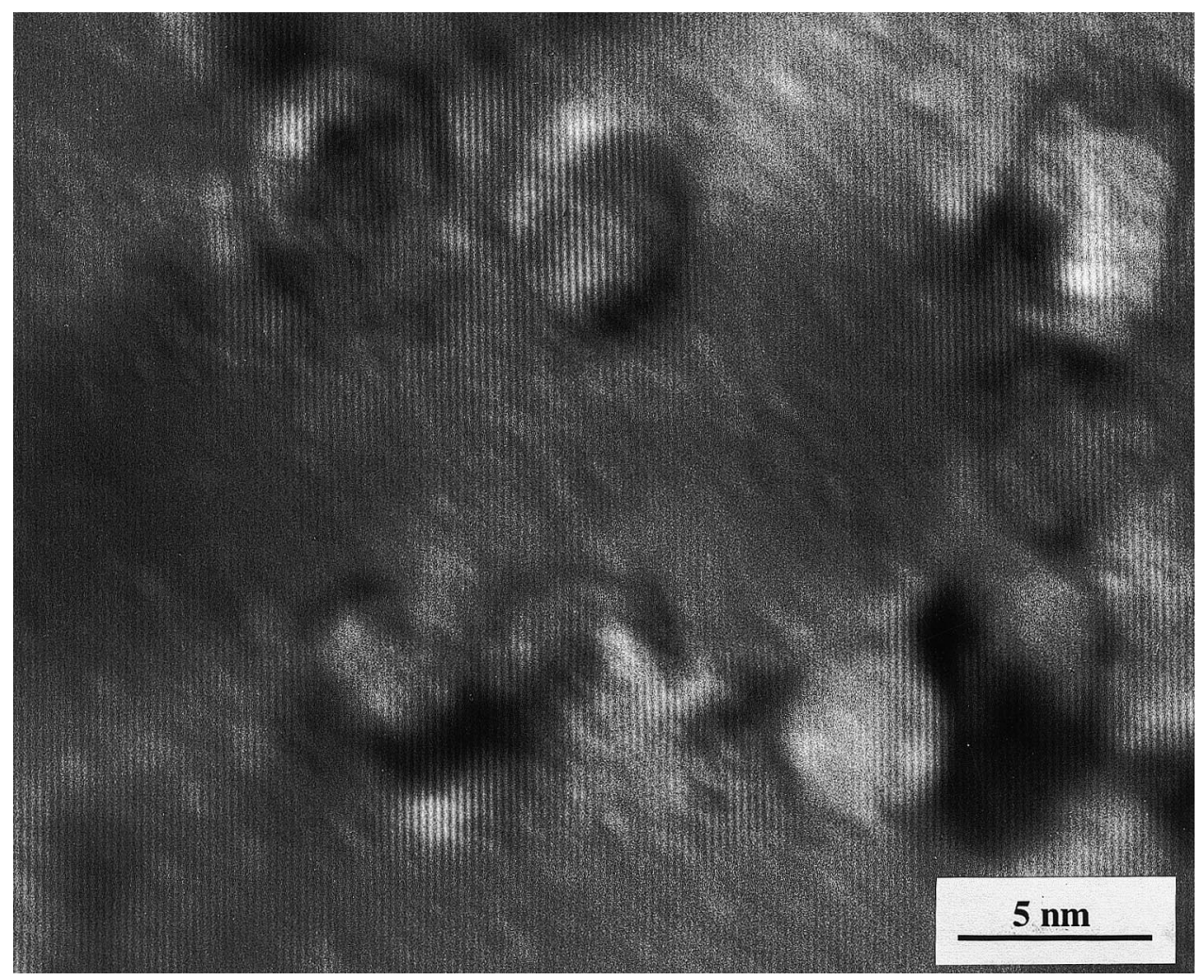

Fig. 2. HREM image of intragranular coherent $\mathrm{MgO}$ precipitates in internally oxidized $\mathrm{Ag} / \mathrm{MgO}$. 


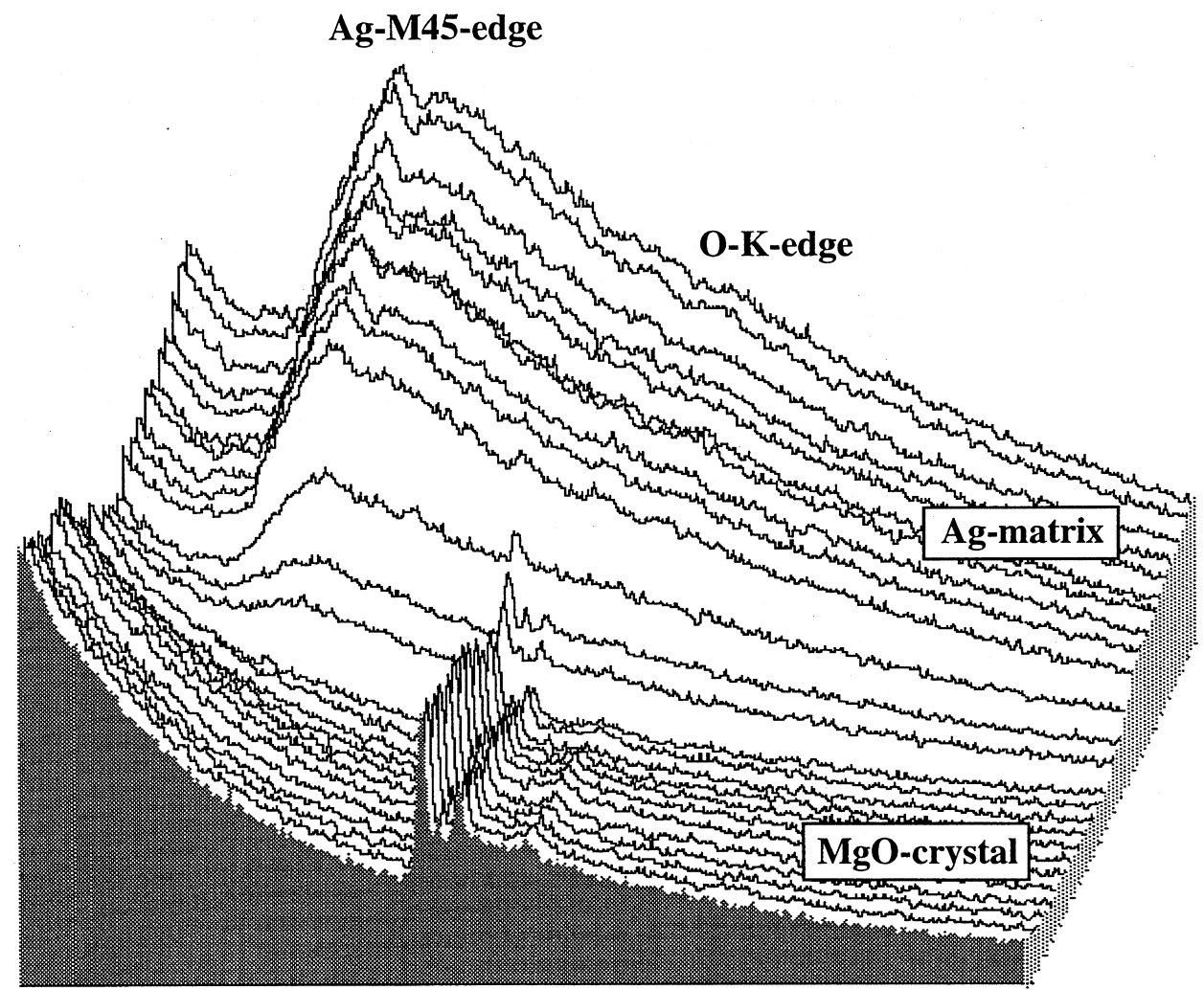

Fig. 3. Set of EEL spectra along a $50 \mathrm{~nm}$ line across the $\mathrm{Ag} / \mathrm{MgO}$ interface (sample annealed in oxygen).

ELNES of this interface-related spectrum is similar to that of $\mathrm{MgO}$ as the larger part of the measuring probe sees the oxygen from the precipitate. However, on the low energy side of the first peak there is a small energy shoulder. This change in the bonding state of oxygen directly at the interface is more pronounced if the normalized spatial difference method is used, i.e. by subtracting the $\mathrm{O}-\mathrm{K}$

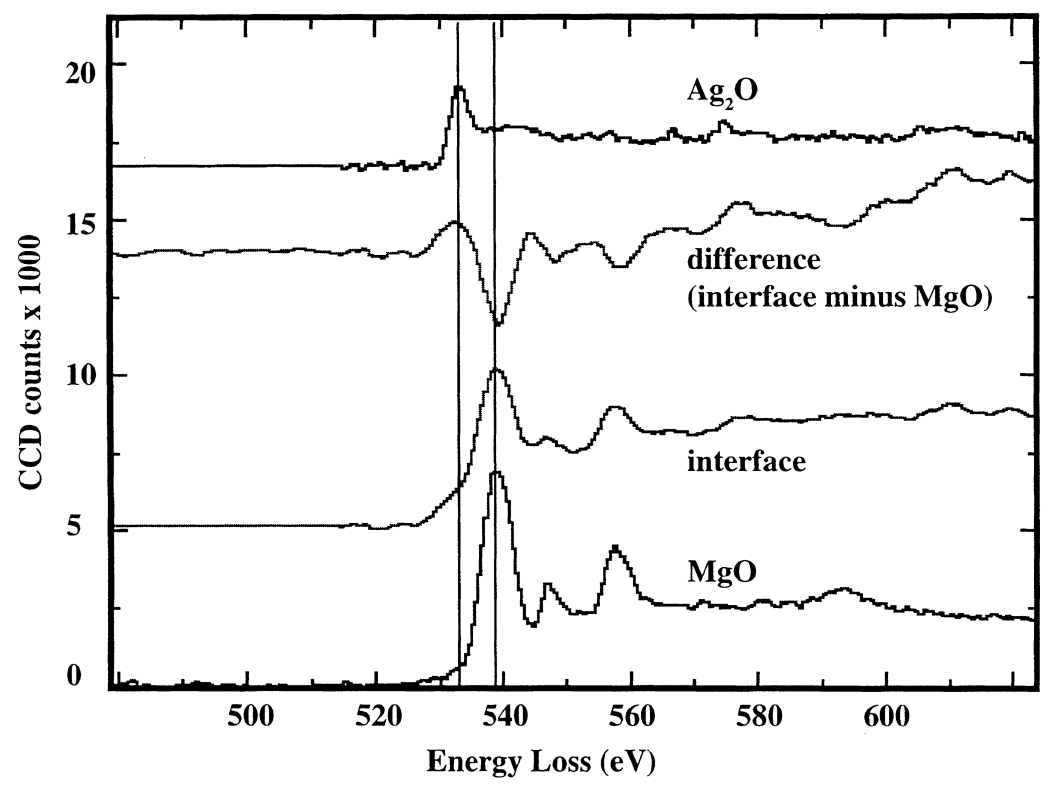

Fig. 4. O-K ELNES at the interface of a sample annealed in oxygen compared with those of $\mathrm{Ag}_{2} \mathrm{O}$ and $\mathrm{MgO}$, difference spectrum: interface minus $\mathrm{MgO}$. 


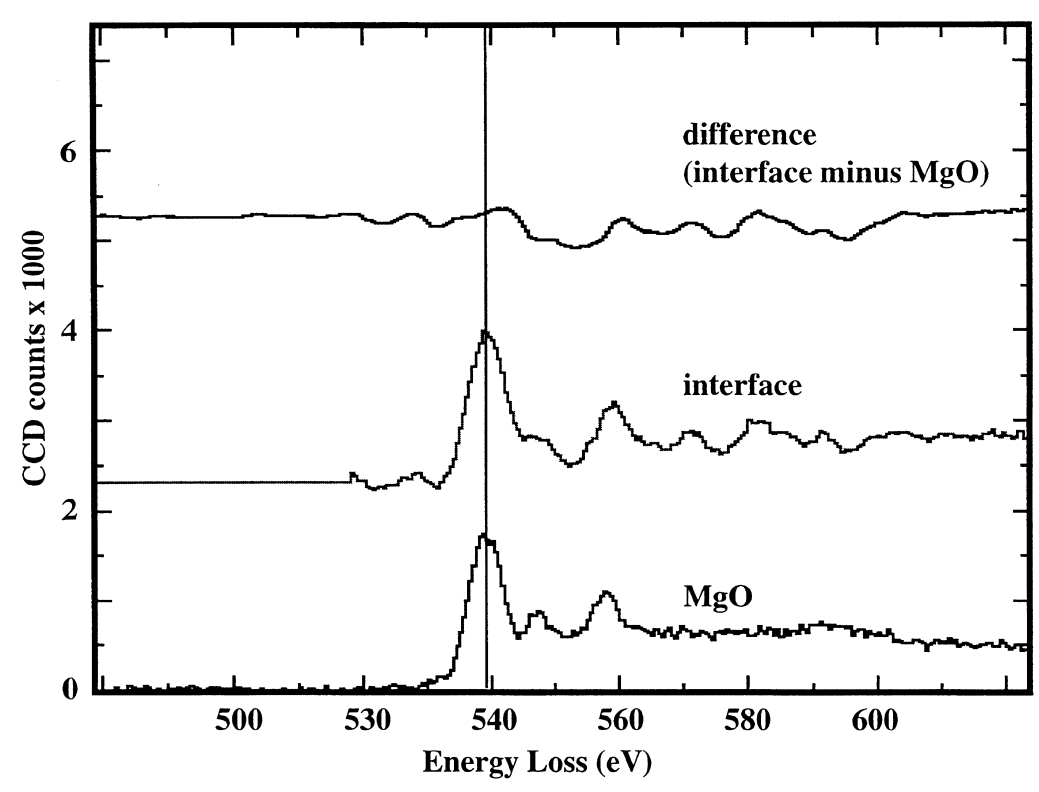

Fig. 5. O-K ELNES at the interface of a sample annealed in vacuum compared with that of $\mathrm{MgO}$, difference spectrum: interface minus $\mathrm{MgO}$.

edge of $\mathrm{MgO}$ from that recorded at the interface, presented as the "difference" curve in Fig. 4. The difference spectrum clearly shows two neighbouring peaks - a positive one and a negative one - at 532 and $539 \mathrm{eV}$, respectively, marked by lines in the figure. These energies just correspond to the characteristic 1s-2p transitions of oxygen in $\mathrm{Ag}_{2} \mathrm{O}$ and $\mathrm{MgO}$, respectively, used as reference standards.

3.2.2. Specimens annealed in vacuum. Using the same method as described above, the bonding state of oxygen has been investigated at the $\mathrm{Ag} / \mathrm{MgO}$ phase boundary of a vacuum annealed material (at $1163 \mathrm{~K}$ for $2 \mathrm{~h}$ ) by taking sets of EEL spectra across the interface between large $\mathrm{MgO}$ precipitates and the Ag matrix. Background-subtracted $\mathrm{O}-\mathrm{K}$ edges of $\mathrm{MgO}$ and a typical edge taken from the interfacial region are shown in Fig. 5. The $\mathrm{O}-\mathrm{K}$ ELNES of the $\mathrm{Ag} / \mathrm{MgO}$ interface now reveals almost the same characteristic features as that of $\mathrm{MgO}$. The onset and peak energies are identical. In particular, the interface spectrum no longer displays a hump in front of the $\mathrm{MgO}$ main peak at $539 \mathrm{eV}$. Even the difference spectrum (interface minus $\mathrm{MgO}$ ), also shown in Fig. 5, does not indicate any oxygen at the interface bound in a way different from $\mathrm{MgO}$.

\section{DISCUSSION}

After annealing an $\mathrm{Ag} / \mathrm{MgO}$ specimen in vacuum, the bonding state of oxygen at the $\mathrm{Ag} / \mathrm{MgO}$ interface is the same as in $\mathrm{MgO}$. Therefore, only oxygen atoms belonging to the stoichiometry of $\mathrm{MgO}$ are present at the phase boundary. This is not the case after annealing the $\mathrm{Ag} / \mathrm{MgO}$ sample in oxygen. The
O-K ELNES, observed at the $\mathrm{Ag} / \mathrm{MgO}$ interface, now reveals a second bonding part of oxygen in addition to the features of $\mathrm{MgO}$, which is characterized by a shoulder near the energy $(\approx 532 \mathrm{eV})$, where the $\mathrm{O}-\mathrm{K}$ ELNES of $\mathrm{Ag}_{2} \mathrm{O}$ has its first maximum.

In a first approximation (i.e. neglecting the special energy distribution of the unoccupied states in the conduction band), the edge onset depends on the core electron energies. The behaviour is elucidated in Fig. 6 for $\mathrm{Ag}_{2} \mathrm{O}$ and $\mathrm{MgO}$ (bonding energies taken from Ref. [42]). As oxygen is rather weakly bound in $\mathrm{Ag}_{2} \mathrm{O}(\Delta E=-0.24 \mathrm{eV})$, its bonding state is not easy to distinguish from that of free oxygen by EELS fine structure analysis due to the limited energy resolution of the spectrometer. This problem does not arise for $\mathrm{MgO}$ due to the much larger difference in the $1 \mathrm{~s}$ electron energies $(\Delta E=-5.90 \mathrm{eV})$. Therefore, it is difficult to decide

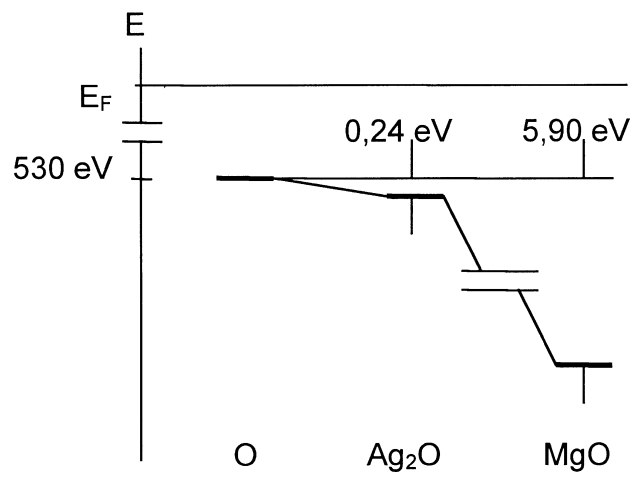

Fig. 6. Comparison between the bonding energies of oxygen in $\mathrm{Ag}_{2} \mathrm{O}$ and $\mathrm{MgO}$. 


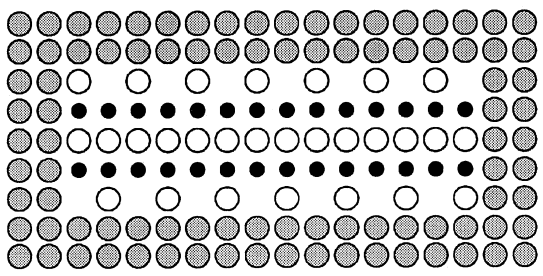

a)
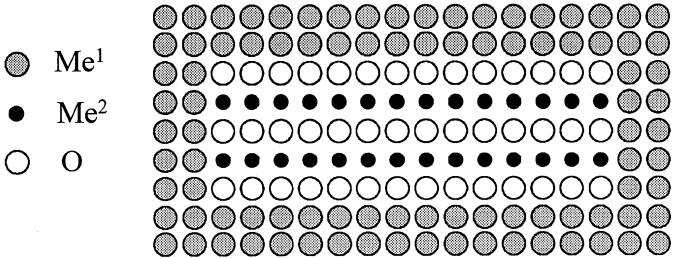

b)

Fig. 7. Structural vacancy model of the segregation of oxygen at $\mathrm{Me}^{1} / \mathrm{Me}^{2} \mathrm{O}$ interfaces (see text).

solely by ELNES, whether the excess oxygen at the interface is bound like $\mathrm{Ag}_{2} \mathrm{O}$, or dissolved as free oxygen, although we can conclude that oxygen segregates at the $\mathrm{Ag} / \mathrm{MgO}$ phase boundaries during the annealing in an oxygen atmosphere. However, quantitative volumetric measurements (sorption and desorption of oxygen [25]) prove that the average free enthalpy of segregation is about $-70 \mathrm{~kJ} / \mathrm{mol} \mathrm{O}$, which is close to the free reaction enthalpy of around $-78 \mathrm{~kJ} / \mathrm{mol} \mathrm{O}$ of the $\mathrm{Ag}_{2} \mathrm{O}$ precipitation from the solid solution of oxygen in silver [39]. Thus we conclude that the excess oxygen covering the $\mathrm{Ag} / \mathrm{MgO}$ interface at high oxygen activities is not free oxygen, but takes an $\mathrm{Ag}_{2} \mathrm{O}$-like bonding state. For the $\mathrm{Cu} / \mathrm{MgO}$ system, the result was simi$\operatorname{lar}[7,24]$.

As the oxygen layer at the $\mathrm{Ag} / \mathrm{MgO}$ interface reveals an $\mathrm{Ag}_{2} \mathrm{O}$ bonding part, we suggest a structural model, which in Fig. 7 is given for the general case of two metals $\mathrm{Me}^{1}$ and $\mathrm{Me}^{2}$. After desorption of oxygen at low oxygen activities (annealing in vacuum), the structural vacancies shown in Fig. 7(a) are empty so that in fulfilling the stoichiometry condition of $\mathrm{MgO}$, only a half-occupied (111) oxygen plane terminates the $\mathrm{MgO}$ crystal. The driving force in the segregation is the reduction of interfacial energy, by filling up the structural vacancies at the phase boundary with excess oxygen.

For oxygen segregation, as shown in Fig. 7(b), the excess oxygen atoms fill up the structural vacancies $(50 \%$ of the atomic surface sites) on the densely packed terminal (111) MgO plane, forming two-dimensional $\mathrm{Ag}_{2} \mathrm{O}$.

The structural vacancy model [25, 27] remains true for more complicated structures and shapes, i.e. fully or truncated octahedral precipitates of $\mathrm{MgO}$, etc. Fully packed and terminal oxygen layers always lead to an excess of oxygen, if the oxygen activity or its partial pressure, respectively, are large enough to saturate the terminal layers. The smaller the precipitates the larger the deviations from stoichiometry as the composition of the interfaces contributes more to the overall composition. This is in agreement with experimental observations for internally oxidized alloys [25]. In a first-order approximation, desorption of excess oxygen should start at oxygen pressures lower than the decompo- sition pressure of the matrix. This prediction is based on the assumption that the excess oxygen is getting its electrons from the matrix metal and, therefore, forming a kind of corresponding twodimensional metal oxide at the interface.

\section{CONCLUSIONS}

High voltage (HVEM) and high resolution electron microscopy (HREM) revealed that $\mathrm{MgO}$ particles typically of about $100 \mathrm{~nm}$ in diameter are arranged along the silver grain boundaries of $\mathrm{Ag} /$ 3 at. $\% \mathrm{Mg}$ alloys. At an atomic level, the chemical composition of their interfaces was studied by electron energy loss (EELS) fine structure analysis especially at the ionization edges (ELNES): after annealing an $\mathrm{Ag} / \mathrm{MgO}$ specimen in vacuum, the bonding state of oxygen at the $\mathrm{Ag} / \mathrm{MgO}$ interface is the same as in $\mathrm{MgO}$. Therefore, only oxygen atoms belonging to the stoichiometry of $\mathrm{MgO}$ are present at the phase boundary. This is not the case after annealing the $\mathrm{Ag} / \mathrm{MgO}$ sample in oxygen. The $\mathrm{O}-\mathrm{K}$ ELNES, observed at the $\mathrm{Ag} / \mathrm{MgO}$ interface, reveals a second bond contribution of oxygen, in addition to the features of $\mathrm{MgO}$, which is characterized by a shoulder near the energy where the O-K ELNES of $\mathrm{Ag}_{2} \mathrm{O}$ has its first maximum $(\approx 532 \mathrm{eV})$.

The suggested structural vacancy model explains the observed segregation of oxygen at $\mathrm{Ag} / \mathrm{MgO}$ interfaces and agrees with the results of numerous investigations in other systems such as $\mathrm{Cu} / \mathrm{MgO}$ or $\mathrm{Pd} / \mathrm{Al}_{2} \mathrm{O}_{3}$. It probably describes a general principle governing the segregation of oxygen at metal/oxide interfaces: the appearance of structural vacancies at terminal close-packed oxide lattice planes that can be filled with excess oxygen. The chemisorption bond then results from the formation of oxide-like bonds between these segregated oxygen atoms and the matrix metal.

Acknowledgements-The authors are grateful to Dipl.-Ing. (FH) Arnold Weible (Max Planck Institute of Metals Research Stuttgart, Institute of Materials Science) for preparing the samples and for performing the annealing treatments. 


\section{REFERENCES}

1. Rühle, M., Evans, A. G., Ashby, M. F. and Hirth, J P. (ed.), Metal-Ceramic Interfaces, in Acta-Scripto Metallurgica Proc. Series 4. Pergamon Press, Oxford, 1990.

2. Gonis, A. and Tuchi, P. (ed.), Stability of Materials. Structure-Property Relationship of Metal-Ceramic Interfaces. Gordon \& Breach, New York, 1996.

3. Winegert, P. C. and Horn, G., I.E.E.E. Trans. Comp. Hybrids Mfg Technol., 1993, 16, 190.

4. Mader, W., Z. Metallk., 1992, 83, 478.

5. Lu, P. and Cosanday, F., Ultramicroscopy, 1992, 40, 271.

6. Benedek, R., Minkoff, M. and Yang, L. H., Phys Rev., 1996, B54, 7697.

7. Imhoff, D., Laurent, S., Colliex, C. and BackhausRicoult, M., Eur. Phys. J., 1999, AP5, 9.

8. Krakauer, B. W. and Seidman, D. N., Phys. Rev., 1993, B48, 6724.

9. Shashkov, D. A. and Seidman, D. N., Phys. Rev. Lett., 1995, 75, 268.

10. Kooi, B. J., Westers, A. R. and De Hosson, J. Th. M., Mater. Sci. Forum, 1999, 294-296, 255.

11. Necker, G. and Mader, W., Phil. Mag. Lett., 1988, 58, 205.

12. Mader, W. and Necker, G., in Stability of Materials Structure-Property Relationship of Metal-Ceramic Interfaces, ed. A. Gonis and P. Tuchi. Gordon \& Breach, New York, 1996, p. 222.

13. Muschik, T. and Rühle, M., Phil. Mag. A, 1992, 65 , 363.

14. Jang, H., Seidman, D. N. and Merkle, K. L., Scripta metall. mater., 1992, 26, 1493.

15. Jang, H. and Seidman, D. N., Interface Sci., 1993, 1, 61.

16. Muller, D. A., Shashkov, D. A., Benedek, R., Yang, L. H., Silcox, J. and Seidman, D. N., Phys. Rev. Lett., 1998, 80, 4741.

17. Lopez, N. and Illas, F., J. Molec. Cat., 1997, A119, 177.

18. Mader, W. and Maier, B., Colloque physique, 1990, C1-51, 867

19. Backhaus-Ricoult, M. and Hagège, S., Phil. Mag. A, 1993, 67, 1471

20. Chen, R. F., et al., Ultramicroscopy, 1994, 54, 179

21. Vellinga, W. P. and De Hosson, J. Th. M., in Intergranular and Interphase Boundaries in Materials, ed. A. C. Ferro, J. P. Conde and M. A. Fortes. Transtec Publications Ltd, Zürich, 1996, p. 361

22. Lopez, N. and Illas, F., J. phys. Chem., 1996, 100, 16275.

23. Groen, H. B., Kooi, B. J., Vellinga, W. P. and De Hooson, J. Th. M., Phil. Mag. A, 1999, 79, 2083.

24. Laurent, S., Imhoff, D., Colliex, C., Hÿtch, M. J., Devaud, J., Hagège, S. and Backhaus-Ricoult, M., Mater. Sci. Forum, 1999, 294-296, 325.

25. Gegner, J., Hörz, G. and Kirchheim, R., Interface Sci., 1997, 5, 231.

26. Huang, X. Y., Mader, W., Eastman, J. A. and Kirchheim, R., Scripta metall. mater., 1988, 22, 1109.

27. Huang, X. Y., Mader, W. and Kirchheim, R., Acta metall. mater., 1991, 39, 893.

28. Scheu, C., Dehm, G., Müllejans, H., Brydson, R. and Rühle, M., Microsc. Microanal. Microstruct., 1995, 6, 19.

29. Brydson, R., Bruley, J., Müllejans, H., Scheu, C. and Rühle, M., Ultramicroscopy, 1995, 59, 81.

30. Jonnard, P., Vergand, F., Hombourger, C. and Bonnelle, C., Proc. J. Automne, 1996, SF2M 1996 191.

31. Backhaus-Ricoult, M., Laurent, S., James, M., Minel, L., Barthés, M. G. and Hagège, S., Proc. J. Automne, 1996, SF2M 1996, 180.

32. Ernst, E., Pirouz, P. and Heuer, A. H., Phil. Mag. A, 1991, 63, 259

33. Ernst, F., Mater. Sci. Engng, 1995, R14, 97.

34. Groen, H. B. and De Hosson, J. Th. M., Scripta mater., 1998, 38, 769.

35. Shashkov, D. A. and Seidman, D. N., Mater. Sci Forum, 1996, 207-209, 429

36. Lichtenberger, O., Schneider, R. and Woltersdorf, J., Physica status solidi (a), 1995, 150, 661.

37. Schneider, R., Lichtenberger, O. and Woltersdorf, J., J. Microsc., 1996, 183(1), 39.

38. Chan, D. K., Seidman, D. N. and Merkle, K. L., Phys. Rev. Lett., 1995, 75, 1118.

39. Fromm, E. and Gebhardt, E., Gase und Kohlenstoff in Metallen. Springer-Verlag, Berlin, 1976.

40. Gegner, J., Thesis, University of Stuttgart, 1995.

41. Brydson, R., Sauer, H., Engel, W. and Zeitler, E., Microsc. Microanal. Microstruct., 1991, 2, 159.

42. Knacke, O., Kubaschewski, O. and Hesselmann, K. (ed.), Thermochemical Properties of Inorganic Substances, 2nd edn. Springer-Verlag, Berlin, 1991. 